\title{
Participação eletrônica, efetividade governamental e accountability
}

\author{
Lamartine Vieira Braga
}

Fundação Getúlio Vargas (FGV)

Ricardo Corrêa Gomes

Universidade de Brasília (UnB)

No contexto atual emerge a Governança Responsiva, modelo orientado por princípios de responsabilização, transparência e participação, em que a efetividade se vincula a seu atributo-chave: a responsividade. Portanto, torna-se fundamental aprofundar o entendimento dessa mudança de paradigma, em particular no que tange ao papel desempenhado pelo governo. $O$ presente artigo tem como objetivo analisar as relações entre o desenvolvimento do governo eletrônico e três aspectos-chave: participação eletrônica, efetividade governamental e responsabilização dos agentes públicos (accountability). Para tanto, lançou-se mão de uma abordagem dedutiva e objetiva da qual derivou uma estratégia de trabalho de natureza quantitativa. Foram selecionados dados secundários, baseados em populações, e também foram adotados critérios de comparação complementares, a partir dos quais realizou-se um estudo comparativo global, de corte transversal (cross-sectional). Em suma, constatou-se que altos índices de desenvolvimento do governo eletrônico estão correlacionados a altos índices de participação eletrônica. Além disso, verificou-se que quanto mais elevado o nível de participação eletrônica, mais elevado o nível de efetividade governamental e também de responsabilização dos agentes públicos.

Palavras-chave: governo eletrônico, participação social, accountability, transparência governamental, efetividade

[Artigo recebido em 21 de maio de 2015. Aprovado em 21 de fevereiro de 2017.] 


\section{Participación electrónica, la efectividad gobiernamental y la responsabilidad}

En el contexto actual surge el modelo de Gobernabilidad Sensible, guiada por los principios de responsabilidad, transparencia y participación, donde la efectividad está ligada a su atributo clave: la capacidad de respuesta. Por lo tanto, es esencial para profundizar en el conocimiento de este cambio de paradigma, en particular en relación con el papel desempeñado por el gobierno. Este artículo tiene como objetivo analizar la relación entre el desarrollo del gobierno electrónico y de tres aspectos fundamentales: la participación electrónica, la efectividad del gobierno y la responsabilidad de los funcionarios públicos. Para ello, se empleó un enfoque deductivo y objetivo del cual derivó una estrategia de trabajo cuantitativa. Se seleccionaron los datos secundarios sobre la base de la población, y también se adoptaron criterios de comparación adicionales, a partir de los cuales se llevó a cabo un estudio comparativo global de corte transversal (cross-sectional). En resumen, se encontró que altos índices de desarrollo de gobierno electrónico se correlacionan con altos índices de participación electrónica. Además, se encontró que cuanto más elevado el nivel de participación electrónica, mayor es el nivel de efectividad del gobierno, así como la responsabilidad de los funcionarios públicos.

Palabras-clave: gobierno electrónico, participación social, accountability, transparencia gubernamental, efectividad

\section{Electronic participation, government effectiveness, and accountability}

At the current context emerges the Responsive Governance, a model driven by principles of accountability, transparency and participation, where effectiveness is linked to its key attribute: responsiveness. This article aims to analyze the relations between the e-government development and three key aspects: electronic participation, government effectiveness and accountability. To do so, it employed a deductive and objective approach, from which derived a working strategy of quantitative nature. Secondary data were selected based on population, and were also adopted additional comparison criteria, from which it was carried out a comparative cross-sectional study. In short, it was found that high rates of development of government are correlated with high levels of electronic participation. Furthermore, it was found that the higher the level of electronic participation the higher the level of government effectiveness and also accountability.

Keywords: electronic government, social participation, accountability, government transparency, effectiveness 


\section{Introdução}

Como o braço formulador e executor das diretrizes políticas dos governos, a administração pública se reveste de importância fundamental no processo de atendimento às demandas da sociedade por parte do Estado. Como a coletividade não é estática, a administração pública vem, desde seu início, sofrendo transformações, a cada mudança de cenário, a fim de auxiliar na tarefa de atender, contínua e satisfatoriamente, aos anseios dos cidadãos. O advento do Estado moderno propiciou a implementação do modelo de burocracia weberiano, denominado de Administração Pública Tradicional (UNITED NATIONS, 2005b), a partir do final do século 18, que veio atender às aspirações dos ex-súditos, agora elevados à categoria de cidadãos, por serviços públicos prestados de maneira imparcial por um corpo profissional de funcionários.

Posteriormente, o fim da chamada Era de Ouro foi marcado pelo esgotamento do Welfare State, nos países desenvolvidos, e pela crise fiscal dos Estados nacionais, nos países em desenvolvimento, dando ensejo ao aparecimento da New Public Management (BARZElay, 2001; BeVIR; RHOdes; Weller, 2003; FATtore; Dubois; LAPENTA, 2012), no final da década de 1970, paradigma importado do setor privado com o objetivo de flexibilizar o Estado em um momento de crescente globalização. No despontar do século 21, as burocracias estatais passam a sofrer pressões no sentido de se tornarem mais responsivas aos cidadãos, em uma atmosfera marcada pela crescente importância do ambiente internacional e consequente diminuição da capacidade dos governos em proteger suas economias e sociedades de influências externas, tais como mercados de capitais globais ou organizações supranacionais, como é o caso da União Europeia.

Em paralelo, novas tecnologias de informação e comunicação (TIC), mais ubíquas e interativas, aceleram a mudança nos padrões de relacionamento entre governo e sociedade, permitindo arranjos mais plurais e democráticos, baseados mais em redes do que em hierarquias (BAKRI, 2004). Poderosos stakeholders não estatais passam a estar cada vez mais envolvidos nos processos decisórios das organizações públicas, dotando os cidadãos de empowerment em suas relações com o Estado. Nesse panorama atual, propõe-se um novo modelo de administração pública: a Governança Responsiva (UNITED NATIONS, 2005b), também denominada de New Public Governance (OSBORNE, 2006) ou Digital-Era Governance (DUNLEAVY et al., 2006). Na verdade, não se trata de um paradigma consolidado, mas de uma tendência contemporânea de desenvolvimento do setor público.

Os princípios orientadores da Governança Responsiva são a responsabilização (accountability), a transparência e a participação. Seu atributo-chave é a 
responsividade, conceito fortemente vinculado à efetividade governamental. Esse modelo inovador desponta em paralelo com formas inéditas de pensar e agir, apoiadas nas modernas TIC, tornando possível uma interface governo-cidadão de mão dupla, via sistemas de comunicação eletrônica e transações seguras no fornecimento de serviços e integração interorganizacional (UNITED NATIONS, 2005b). Espera-se que esse novo paradigma ofereça respostas aos inúmeros desafios atualmente impostos aos Estados, entre os quais é possível identificar três exemplos.

Com efeito, a possibilidade de maior acesso a informações e ao conhecimento, proporciona-do pelas novas TIC, permite um processo de tomada de decisão ao mesmo tempo mais disperso e mais transparente, aumentando o nível de responsabilização de políticos e de servidores públicos. Não obstante, essa possibilidade, em grande parte do mundo, ainda não se tornou algo concreto. Os governos, principalmente nos países em desenvolvimento, têm elevada responsabilidade no que tange à superação do chamado digital divide, proporcionando aos seus cidadãos oportunidades de desenvolvimento econômico e social (Braga, 2007; Compaine, 2001; Warschauer, 2006). Além disso, há, ainda, a necessidade de se avançar em questões relacionadas à dependência tecnológica, censura governamental e quebra de privacidade no espaço virtual (BASU, 2004; Braga, 2009; CoOK; Horobin, 2006; FernedA; Alonso; BragA, 2011; PETLEY, 2013).

O segundo desafio reside, paradoxalmente, no surgimento do governo eletrônico, o qual tem permitido, cada vez mais, que os cidadãos tenham acesso a serviços públicos personalizados, de maior qualidade, sem necessidade de se ater a horários e locais específicos de atendimento, minimizando a perda de tempo em filas e deslocamentos desnecessários. Por conseguinte, esses avanços em termos de efetividade resultarão em novas pressões exercidas sobre o Estado (Miguel-MolinA, 2010). Nos países desenvolvidos, essas pressões se darão no sentido de conservar os benefícios sociais em face de reformas do Estado visando à contenção de gastos, em decorrência da crise econômica e financeira global iniciada em 2008. Ou seja, ao mesmo tempo em que se exige a manutenção dos altos níveis de efetividade governamental atingidos no auge do Estado de bem-estar social, requer-se que os mesmos resultados sejam alcançados, cada vez mais, de modo eficiente. Nos países em desenvolvimento, por seu turno, o Estado passará a sofrer pressões no sentido não apenas de manter, mas de criar Welfare States.

Em terceiro e último lugar, a questão da participação eletrônica é também um grande desafio enfrentado atualmente pelos governos. Mais uma vez, o advento das 
modernas TIC desempenha um papel fundamental nesse processo. Um exemplo recente da expressão desse fenômeno foi a utilização, com sucesso, da Web 2.0 (cyber-campaigning, cyber-fundraising) durante a vitoriosa campanha presidencial de Barack Obama nos Estados Unidos da América (EUA) em 2008 (AsSMANN; MASLOW, 2010; GIBSON, 2009; LEE, 2009).

Em vista dessas considerações iniciais, este trabalho tem como objetivo analisar as relações entre o desenvolvimento do governo eletrônico e três aspectos-chave: participação eletrônica, efetividade governamental e responsabilização dos agentes públicos (accountability). Para tal, lançou-se mão de uma abordagem de pesquisa dedutiva e objetiva e de uma metodologia de cunho quantitativo. Em primeiro lugar, são examinadas as relações existentes entre indicadores de participação eletrônica e desenvolvimento do governo eletrônico (como um todo e também especificamente no que tange à disponibilização de informações e serviços públicos). Em segundo lugar, são estudadas as correlações entre participação eletrônica e efetividade governamental. Por fim, analisam-se as relações entre participação eletrônica e accountability.

Este trabalho organiza-se a partir da presente introdução e se desenvolve em outras quatro seções: breve referencial teórico e respectivo desmembramento de modelo teórico e derivação de hipóteses de pesquisa; metodologia de pesquisa; apresentação e discussão dos resultados; e explicitação das conclusões e recomendações da pesquisa.

\section{Referencial teórico e derivação de hipóteses de pesquisa}

Na literatura, a participação eletrônica nos processos políticos e na formulação e implementação de políticas públicas se encontra frequentemente associada ao desenvolvimento do governo eletrônico. Vários autores sugerem que há valores democráticos inerentes às TIC empregadas pelo governo, as quais estão transformando as relações Estado-sociedade, pela maior interatividade e ubiquidade (Alonso; Ferneda; Braga, 2011; Bimber, 2000, 2001; Center for Democracy ANd TeChNology, 2002; ChadWICK; MaY, 2003; Coleman, 1999; DAWES; GregG; Agouris, 2004; EuRopeAn CoMmunities, 2003; GIBSON; LUSOLI; WARD, 2005; JAEGER, 2003; KERSTEN, 2003; LAMBRINOUDAKIS et al., 2003; LÉVY, 2004; LÖFSTEDT, 2005; MISURACA, 2009; NATIONAL INFORMATION SOCIETY AGENCY, 2008; PINA; TORRES; Royo, 2007; REECE, 2006; RoberTSON; VATRAPU, 2010; STAHL, 2005; StARR, 2010; UNITED NATIONS, 2003, 2004, 2005a, 2005b, 2008; UNITED NATIONS; AMERICAN SOCIETY fOr PUblic Administration, 2002). Isso possibilita a dedução das hipóteses a seguir: 
H1: Um alto grau de participação eletrônica está positivamente correlacionado com um alto grau de desenvolvimento do governo eletrônico, como um todo.

H2: Um alto grau de participação eletrônica está positivamente correlacionado com um alto grau de desenvolvimento do governo eletrônico, especificamente no que tange à disponibilização de informações e serviços.

Nesse contexto, é digna de nota a relação existente entre participação eletrônica e a emergência do novo modelo de administração pública descrito anteriormente, a chamada Governança Responsiva (BRAGA et al., 2008; DAWES, 2008; HAMMERMAN, 2005; LIM; TANG, 2008; LÖFSTEDT, 2005; MISURACA, 2009; PINA; TORRES; RoYo, 2007; ROBERTSON; VATRAPU, 2010), em que a efetividade governamental e a responsabilização se encontram intimamente vinculadas com a participação eletrônica. Essa visão é compartilhada pela União Europeia, onde há entendimento de que a qualidade, a relevância e a efetividade das políticas governamentais dependem da capacidade de se assegurar uma ampla participação eletrônica, em todas as instâncias de tomada de decisão, desde a concepção à implementação (EUROPEAN UNION, 2001).

Para Polat (2005), a noção de governança, enquanto contraposta à noção de governo, se refere à participação de diferentes comunidades dentro de uma estrutura que modifica as relações tradicionais entre o Estado e a sociedade, afetando profundamente o papel desempenhado pelos políticos eleitos, especialmente no que tange ao seu grau de responsabilização. A partir dessa abordagem, formulamse as seguintes hipóteses:

H3: Quanto mais elevado o nível de participação eletrônica, mais elevado o nível de efetividade governamental.

H4: Quanto mais elevado o nível de participação eletrônica, mais elevado o nível de responsabilização dos agentes públicos (accountability).

Entretanto, enquanto há autores mais otimistas, que vislumbram o retorno à democracia direta, composta por cidadãos fortemente empoderados, há outros, mais pessimistas, que anteveem a emergência da democracia "push-button", com a consequente fragmentação da esfera pública.

A primeira visão remonta a obras de Dyson (1998); Negroponte (1995); Rash (1997); Rheingold (1995); e Toffler e Toffler (1995), nas quais a internet, recentemente comercializada, a par de outras modernas TIC, seria o instrumento de retorno à democracia de estilo ateniense, pensamento retomado por estudos posteriores (BIMBer, 2000, 2001; Coleman, 2005; Gibson, 2001; HeInTZE; BretSChNeider, 2000; Kellogg; Mathur, 2003; ORganisation for ECONOMiC COOPERATION AND DeVelopment, 2003b; SCOtt, 2006; Stanley; Weare, 2004). 
Essa visão, denominada de mobilization theory, sugere que a internet ajuda a criar novas oportunidades para os indivíduos politicamente marginalizados, amplificando suas vozes no processo político (NoRRIS, 2001). Para Becker (2001), as TIC permitem que um amplo número de cidadãos, mesmo localizados fisicamente a grandes distâncias, rapidamente acessem informações governamentais e comuniquem suas opiniões aos líderes políticos. A capacidade das TIC ajuda a expandir oportunidades plebiscitárias, como é o caso de iniciativas de cidadãos ou referendos, os quais empoderam os cidadãos tornando-os diretamente tomadores de decisão (LIM; TANG, 2002).

A segunda visão, conhecida como normalisation thesis, segundo a qual a internet simplesmente reproduziria e reforçaria os comportamentos já existentes no que se refere à participação popular, é defendida por uma série de autores (KRAUT et al., 1998; NorRIS, 2001, 2002; SCHUefele; NISBET, 2002; Weber; LOUMAKE; Bergman, 2001; WELLMAN et al., 2001).

Não obstante, há trabalhos indicando problemas na aceitação dessa visão como uma teoria global, apontando, inclusive, a necessidade da realização de outros estudos de caráter mais ampliado (GIBSON; LUSOLI; WARD, 2005; KRUEGER, 2002; SHAH; KWAK; HOLBERT, 2001; TOlBERT; MCNEAL, 2003). Além disso, cumpre ressaltar que a possibilidade de aperfeiçoamento da participação popular depende de outros fatores abordados anteriormente, como o grau de acesso a informações e de transparência governamental.

De acordo com a Organização das Nações Unidas (ONU), a participação da sociedade, via governo eletrônico (ou participação eletrônica), é definida como o somatório tanto de programas governamentais de encorajamento à participação dos cidadãos, quanto da propensão destes de efetivamente fazê-lo; ou seja, compreende tanto o lado da demanda quanto o lado da oferta nas interações descritas anteriormente como G2C: transações envolvendo governo e consumidores finais ou cidadãos (UNITED NATIONS, 2012).

Segundo Abramson, Arterton e Orren (1988), há, primordialmente, três modalidades de democracia reconhecidas pela Ciência Política relevantes no que tange aos efeitos de novas TIC: plebiscitária, comunitária e pluralista. A primeira é descrita como algo à semelhança da democracia direta, sendo fortemente dependente de instituições e processos (por exemplo, um referendo). A democracia comunitária, por sua vez, é caracterizada mais como um processo orgânico que emerge de uma comunidade composta por iguais; essa modalidade parece ter muito em comum com as interpretações socialistas ocidentais sobre o assunto. $A$ democracia pluralista, por fim, baseia-se na concepção da competição entre grupos descrita por Dahl (1971). 
Sobre a democracia plebiscitária, cabe um aprofundamento. Suas bases remontam à chamada Teoria da Democracia Direta (KANG; GEARHART, 2010), segundo a qual a democracia funciona melhor quando os cidadãos se envolvem diretamente nos debates políticos, na tomada de decisão e na própria ação; nesse contexto, as TIC contemporâneas seriam o elo entre cidadãos desengajados e processos políticos envolvendo questões públicas (HAGUE; LOADER, 1999).

Nesse contexto, o papel desempenhado por websites governamentais na promoção da "teledemocracia", por meio de recursos action-related, tais quais formulários online, ferramentas de votação eletrônica, fóruns de discussão online, e-consultations e virtual meetings, é fundamental (HYSON, 2010; NORRIS, 2002; WORLD BANK, 2013). Scott (2006) alerta, ainda, que o processo de democracia direta também requer dos governos políticas e programas específicos que reflitam o conhecimento coletivo e o comprometimento dos cidadãos. Ademais, são necessárias normas de governança da interatividade no chamado cyberspace, provendo regras que organizem a participação da sociedade nos processos supracitados (MARLIN-BENNETT; THORNTON, 2012). Sob a ótica da governança do setor público, a participação da sociedade reside, hoje, no coração do novo paradigma dos sistemas democráticos de governo (FREDERICKSON, 1991; KETTL, 2002, 2006).

Enquanto alguns teóricos da democracia têm discutido sobre o declínio das instituições representativas (FISHKIN, 1991; NABATCHI, 2010; SKOCPOL, 2002), outros autores, por seu turno, têm se referido a novas formas de engajamento da população em movimentos denominados de democracia deliberativa (FUNG; WRIGHT, 2001; SIRIANNI, 2009), os quais ofereceriam aos cidadãos novas oportunidades de participação, aumentando, por conseguinte, a transparência, a responsabilização e a legitimidade governamentais (BRYSON; CROSBY; STONE, 2006; EMERSON; NABATCHI; BALOGH, 2012).

De acordo com Johnston (2010), a participação da sociedade depende de uma infraestrutura de governança, a qual se define como sendo a "coleção de tecnologias, sistemas, pessoas, políticas, práticas e relacionamentos que interagem a fim de suportar as atividades governamentais". Ainda de acordo com esse autor, as TIC seriam ferramentas de incremento da capacidade da sociedade de organizar, interagir e governar.

Segundo Polat (2005), a governança contemporânea se inclina a abrir canais de participação e arenas de deliberação aos cidadãos. Essa dimensão democrática da governança requer o uso da internet como canal privilegiado, o qual atuaria no sentido de gerar cada vez mais participação dos cidadãos, por meio de ferramentas como online polls, discussion forums, e outras formas de online consultation. O Quadro 1 traz um sumário das hipóteses derivadas das categorias de análise da pesquisa. 
Quadro 1 - Sumário das hipóteses de pesquisa por categorias de análise

\begin{tabular}{|c|l|}
\hline $\begin{array}{c}\text { Categorias de } \\
\text { análise }\end{array}$ & \multicolumn{1}{c|}{ Hipótese } \\
\hline Participação Eletrônica & $\begin{array}{l}\text { H1: Um alto grau de participação eletrônica está } \\
\text { positivamente correlacionado com um alto grau de } \\
\text { desenvolvimento do governo eletrônico, como um todo. }\end{array}$ \\
\cline { 2 - 3 } & $\begin{array}{l}\text { H2: Um alto grau de participação eletrônica está } \\
\text { positivamente correlacionado com um alto grau de } \\
\text { desenvolvimento do governo eletrônico, especificamente } \\
\text { no que tange à disponibilização de informações e serviços. }\end{array}$ \\
\hline $\begin{array}{c}\text { Participação eletrônica e } \\
\text { efetividade governamental }\end{array}$ & $\begin{array}{l}\text { H3: Quanto mais elevado o nível de participação } \\
\text { eletrônica, mais elevado o nível de efetividade } \\
\text { governamental. }\end{array}$ \\
\hline Participação eletrônica e & $\begin{array}{l}\text { H4: Quanto mais elevado o nível de participação } \\
\text { eletrônica, mais elevado o nível de responsabilização dos } \\
\text { agentes públicos (accountability). }\end{array}$ \\
\hline
\end{tabular}

Fonte: Elaboração própria.

\section{Metodologia de pesquisa}

\section{Seleção e coleta dos dados}

Neste trabalho, optou-se por dois conjuntos de dados secundários obtidos a partir de duas grandes pesquisas mundiais: a E-government Survey 2012, realizada pela Organização das Nações Unidas (UNITEd NATIONS, 2012), e a Worldwide Governance Indicators 2011 Update, realizada pelo Banco Mundial (KAUFMANN; KrAAY; MAStRuzZI, 2011). De acordo com Bryman (2008), o uso de dados secundários remete à chamada análise secundária, ou seja, a apreciação de dados por pesquisadores que não estiveram envolvidos no seu processo de coleta.

Antes da descrição das variáveis de pesquisa, são feitas três considerações sobre o par de conjuntos de dados utilizados. A primeira é que, em ambos os casos, tratase de uma abordagem de mensuração que pondera que o fenômeno que se procura medir abrange diferentes dimensões, como é o caso de conceitos como governo eletrônico, participação eletrônica, efetividade governamental e accountability. A ideia por trás dessa abordagem é que, quando o pesquisador está procurando desenvolver a medida de um fenômeno, os diferentes aspectos ou componentes desse conceito devem ser sopesados (LAZARSFELD, 1958). A segunda consideração sobre os conjuntos de dados utilizados neste trabalho é que, em ambos os casos, não se baseiam em amostras, mas na população total, o que proporciona a oportunidade de se obter um panorama completo dos fenômenos abordados (BRYMAN; CRAMER, 2011). A terceira e última consideração sobre os conjuntos de 
indicadores usados neste estudo é que a utilização de dados secundários apresenta uma série de vantagens, quando comparada com a análise de dados primários, conforme descrito a seguir (DALE; ARBER; PROCTOR, 1988):

a) economia de tempo e de recursos no processo de coleta. Como consequência, pode ser dedicado mais tempo especificamente à etapa de análise de dados;

b) acesso a dados de alta qualidade. Geralmente, trata-se de dados obtidos por meio de procedimentos rigorosos de coleta, com alcance de ampla cobertura, muitas vezes abrangendo níveis nacionais ou internacionais e contando com a participação de pesquisadores altamente qualificados na empreitada;

c) oportunidade para realização de variadas análises: cortes longitudinais, transversais (cross-section) e de subgrupos; e

d) possibilidade de haver novas interpretações a partir da reanálise dos dados, ou seja, há, virtualmente, infinitas diferentes formas de se trabalhar com os dados do que aquela em que foi realizada a análise primária.

\section{Variáveis de pesquisa}

A partir dos dois conjuntos de dados secundários escolhidos para este estudo, foram selecionados cinco indicadores para serem utilizados como variáveis representativas do presente modelo teórico de pesquisa: dois relativos ao governo eletrônico, um relativo à participação eletrônica, um relativo à efetividade governamental e um relativo à accountability, cujas características primordiais se encontram sumarizadas no Quadro 2.

\section{Quadro 2 - Características das variáveis de pesquisa}

\begin{tabular}{|l|l|l|l|l|l|}
\hline Variável & $\begin{array}{l}\text { Tipo de } \\
\text { escala de } \\
\text { medida }\end{array}$ & $\begin{array}{l}\text { Amplitude } \\
\text { de } \\
\text { variação }\end{array}$ & $\begin{array}{l}\text { Tamanho } \\
\text { do } \\
\text { universo }\end{array}$ & $\begin{array}{l}\text { Data de } \\
\text { coleta } \\
\text { primária }\end{array}$ & Fonte primária \\
\hline $\begin{array}{l}\text { E-Government } \\
\text { Development } \\
\text { Index (EGDI) }\end{array}$ & Intervalar & $0-1$ & 193 países & 2012 & $\begin{array}{l}\text { United Nations } \\
\text { E-Government Survey }\end{array}$ \\
\hline Serviços online & Intervalar & $0-1$ & 193 países & 2012 & $\begin{array}{l}\text { United Nations } \\
\text { E-Government Survey }\end{array}$ \\
\hline $\begin{array}{l}\text { Participação } \\
\text { eletrônica }\end{array}$ & Intervalar & $0-1$ & 193 países & 2012 & $\begin{array}{l}\text { United Nations } \\
\text { E-Government Survey }\end{array}$ \\
\hline $\begin{array}{l}\text { Voz e } \\
\text { responsabi- } \\
\text { lização }\end{array}$ & Intervalar & $-2,5-2,5$ & $\begin{array}{l}213 \text { países e } \\
\text { territórios }\end{array}$ & 2011 & $\begin{array}{l}\text { World Bank Worldwide } \\
\text { Governance Indicators }\end{array}$ \\
\hline $\begin{array}{l}\text { Efetividade } \\
\text { governamental }\end{array}$ & Intervalar & $-2,5-2,5$ & $\begin{array}{l}213 \text { países e } \\
\text { territórios }\end{array}$ & 2011 & $\begin{array}{l}\text { World Bank Worldwide } \\
\text { Governance Indicators }\end{array}$ \\
\hline
\end{tabular}

Fonte: Elaboração própria. 
A fim de se realizar comparações continentais entre blocos de países, este trabalho adotou o critério de agrupamento oriundo da classificação da United Nations Statistics Division ${ }^{1}$. De acordo com essa classificação, os 193 países membros da ONU são divididos em cinco continentes (com as respectivas subdivisões internas a cada bloco): África (54 países), Américas (35 países), Ásia (47 países), Europa (43 países) e Oceania (14 países).

Cabe esclarecer que, embora os indicadores escolhidos para representar as dimensões do governo eletrônico alcancem, em alguns casos, uma cobertura de até 213 países e territórios, este trabalho considerou apenas aqueles integrantes da ONU, pois a pesquisa sobre governo eletrônico a partir da qual se extraíram os dados secundários leva em conta somente os membros daquela entidade. Além disso, embora a ONU conte, a partir de 2012, com 193 países, foram considerados apenas 192, pois, na pesquisa do Banco Mundial de 2011, o Sudão do Sul ainda não figura como um Estado independente.

As três variáveis selecionadas para representar as dimensões do governo eletrônico foram as seguintes: E-Government Development Index (EGDI), serviços online (componente do EGDI) e participação eletrônica. Trata-se de indicadores oriundos da pesquisa global sobre governo eletrônico realizada pela $\mathrm{ONU}^{2}$ (United Nations E-government Survey) desde 2002. Nesse ano, excepcionalmente, o trabalho foi realizado em parceria com a American Society for Public Administration (United Nations; American Society for Public Administration, 2002). As demais pesquisas foram realizadas nos anos de 2003, 2004, 2005, 2008, 2010 e 2012 (UNITEd Nations, 2003, 2004, 2005a, 2008, 2010, 2012).

Esses estudos têm como objetivo fornecer indicações sobre o grau de desenvolvimento do governo eletrônico aos formuladores de políticas públicas e profissionais que atuam nessa área. De acordo com seu modelo conceitual, o EGDI é um indicador composto a partir de três dimensões: serviços online, infraestrutura de telecomunicações e capital humano. A dimensão participação eletrônica também é medida pela ONU, desde 2003, no âmbito de suas pesquisas sobre governo eletrônico, embora não integre a composição do EGDI, constituindo-se em um indicador suplementar. O Quadro 3 detalha as características dos indicadores formadores do EGDI e também do indicador suplementar participação eletrônica.

\footnotetext{
${ }^{1}$ Maiores detalhes podem ser obtidos a partir do sítio: http://unstats.un.org/unsd/methods/m49/m49regin.htm.

2 Department of Economic and Social Affairs.
} 
Quadro 3 - Características dos componentes do EGDI e do indicador participação eletrônica

\begin{tabular}{|c|c|c|c|}
\hline Componente & Natureza do indicador & Aspectos considerados & $\begin{array}{c}\text { Peso na } \\
\text { formação do } \\
\text { EGDI }\end{array}$ \\
\hline Serviços online & Qualitativo & $\begin{array}{l}\text { Disponibilização } \\
\text { de informações e } \\
\text { serviços eletrônicos } \\
\text { de governo em seis } \\
\text { áreas: educação, saúde, } \\
\text { tributação, previdência } \\
\text { social, trabalho e meio } \\
\text { ambiente }\end{array}$ & $1 / 3$ \\
\hline $\begin{array}{l}\text { Infraestrutura de } \\
\text { telecomunicações }\end{array}$ & Quantitativo & $\begin{array}{l}\text { Capacidade } \\
\text { infraestrutural de } \\
\text { conectividade de } \\
\text { telecomunicações } \\
\text { de um determinado } \\
\text { país no que tange à } \\
\text { disponibilização de } \\
\text { serviços eletrônicos }\end{array}$ & $1 / 3$ \\
\hline Capital humano & Quantitativo & $\begin{array}{l}\text { Grau de } \\
\text { desenvolvimento social } \\
\text { de acordo com critérios } \\
\text { adotados pela área de } \\
\text { educação }\end{array}$ & $1 / 3$ \\
\hline $\begin{array}{l}\text { Participação } \\
\text { eletrônica }\end{array}$ & Qualitativo & $\begin{array}{l}\text { Nível de utilidade de } \\
\text { serviços eletrônicos do } \\
\text { quarto estágio (serviços } \\
\text { conectados) do primeiro } \\
\text { componente do EGDI } \\
\text { (serviços online) }\end{array}$ & - \\
\hline
\end{tabular}

Fonte: Elaboração própria a partir de informações provenientes de United Nations (2012).

O EGDI leva em conta tanto a capacidade quanto a disposição do setor público na implementação de TIC, considerando não somente a execução das funções de governo e a disponibilização de serviços públicos, mas também o aprimoramento da informação e do conhecimento para os cidadãos. De acordo com esse conceito, o termo capacidade representa a competência sistêmica do Estado em termos financeiros, regulatórios, administrativos, infraestruturais e humanos. Já o significado do termo disposição reside no comprometimento governamental na provisão de informações e conhecimento aos cidadãos, a fim de aumentar seu empowerment (UNITED NATIONS, 2005a).

Ademais, cabe destacar que esse indicador busca compreender de uma forma ampla um fenômeno complexo, como é o caso do governo eletrônico, abrangendo 
aspectos tecnológicos, como características técnicas dos websites; políticos, como as estratégias nacionais de governo eletrônico; e humanos, como o nível de desenvolvimento social (UNITED NATIONS, 2004, 2005a, 2010).

O primeiro componente do EGDI, o indicador serviços online, busca aferir o desempenho dos países segundo um modelo de maturidade de quatro estágios, descrito no Quadro 4. Esse modelo assume, baseado na observação extensiva e reflexão entre experts, que os países, corriqueiramente, iniciam seu desenvolvimento com uma presença emergente online com websites simples, progridem para um estado aperfeiçoado, com a implantação de conteúdo multimídia e interação de duas vias, avançam para um nível transacional com vários serviços providos online e governos solicitando inputs dos cidadãos em matérias de políticas públicas, para, finalmente, alcançar um estado de rede conectada de funções integradas, com compartilhamento de dados generalizado e consulta rotineira aos cidadãos usando redes sociais e ferramentas relacionadas (UNITED NATIONS, 2010).

\section{Quadro 4 - Modelo de maturidade de quatro estágios do índice serviços online}

\begin{tabular}{|c|c|c|}
\hline Estágio & Descrição & $\begin{array}{c}\text { Peso na } \\
\text { formação do } \\
\text { indicador (\%) }\end{array}$ \\
\hline $\begin{array}{l}\text { (I) Serviços } \\
\text { informacionais } \\
\text { emergentes }\end{array}$ & $\begin{array}{l}\text { Websites governamentais disponibilizam informações } \\
\text { sobre políticas públicas, governança, legislação, } \\
\text { regulamentos, documentação relevante e tipos de } \\
\text { serviços públicos oferecidos. Há links para várias } \\
\text { entidades de governo. Os cidadãos podem facilmente } \\
\text { obter informações sobre o que há de novo, assim como } \\
\text { seguir links para informações arquivadas. }\end{array}$ & 7 \\
\hline $\begin{array}{l}\text { (II) Serviços } \\
\text { informacionais } \\
\text { aprimorados }\end{array}$ & $\begin{array}{l}\text { Websites governamentais disponibilizam comunicação } \\
\text { eletrônica aprimorada em uma ou duas vias entre } \\
\text { governo e cidadãos, tais como formulários passíveis de } \\
\text { download para serviços públicos. Os sites dispõem de } \\
\text { recursos de áudio e vídeo, além de estarem disponíveis } \\
\text { em vários idiomas. }\end{array}$ & 24 \\
\hline $\begin{array}{l}\text { (III) Serviços } \\
\text { transacionais }\end{array}$ & $\begin{array}{l}\text { Websites governamentais travam comunicação eletrônica } \\
\text { em duas vias entre governo e cidadãos, incluindo a } \\
\text { requisição e o recebimento de inputs sobre políticas e } \\
\text { programas de governo e seus respectivos instrumentos } \\
\text { regulatórios. Algum tipo de autenticação eletrônica } \\
\text { por parte dos cidadãos é requerida a fim de efetuar } \\
\text { as transações de maneira satisfatória. Os governos } \\
\text { processam transações de vários tipos, como é o caso de } \\
\text { votações eletrônicas; upload e download de formulários; } \\
\text { pagamento de taxas online; e solicitações de certificados, } \\
\text { licenças e permissões. Quando são realizadas transações } \\
\text { financeiras, como transferências de valores, o governo } \\
\text { provê uma rede segura para esse fim. }\end{array}$ & 30 \\
\hline
\end{tabular}




\begin{tabular}{|l|l|l|}
\hline \multicolumn{1}{|c|}{ Estágio } & \multicolumn{1}{|c|}{ Descrição } & $\begin{array}{c}\text { Peso na } \\
\text { formação do } \\
\text { indicador (\%) }\end{array}$ \\
\hline \multirow{3}{*}{$\begin{array}{l}\text { (IV) Serviços } \\
\text { conectados }\end{array}$} & $\begin{array}{l}\text { Websites governamentais mudam a forma como os } \\
\text { governos se comunicam com os cidadãos, destacando-se } \\
\text { a proatividade daqueles na requisição de informações } \\
\text { e opiniões destes lançando-se mão da Web 2.0 e } \\
\text { de outras ferramentas interativas. Serviços e outras } \\
\text { soluções eletrônicas transpassam ministérios e outros } \\
\text { órgãos governamentais de forma ininterrupta. Dados, } \\
\text { informações e conhecimento são transferidos entre } \\
\text { agências de governo por meio de aplicações integradas. } \\
\text { Neste estágio, os governos deixam de estar centrados } \\
\text { em si mesmos e passam a estar centrados no cidadão, } \\
\text { passando a oferecer serviços feitos sob medida para os } \\
\text { indivíduos. Em suma, os governos criam um ambiente } \\
\text { mais propício ao envolvimento dos cidadãos com as } \\
\text { atividades governamentais, dotando-os de voz ativa } \\
\text { nos processos de tomada de decisão e reforçando seu } \\
\text { empowerment. }\end{array}$ & \\
\hline
\end{tabular}

Fonte: Elaboração própria a partir de informações provenientes de United Nations (2012).

Com a finalidade de se obter o conjunto de índices do indicador serviços online, os pesquisadores acessam os principais websites governamentais de cada país, abrangendo: o portal central; o portal de serviços eletrônicos; o portal de participação eletrônica; os sítios dos ministérios da educação, do trabalho, da assistência social, da saúde, da fazenda e do meio ambiente, quando disponíveis. Além de os pesquisadores analisarem seus conteúdos e características, os websites nacionais sofrem uma avaliação acerca dos níveis mínimos referentes à acessibilidade e conteúdos disponíveis de acordo com critérios definidos pelo Web Content Accessibility Guidelines of the World Wide Web Consortium ${ }^{3}$ (UNITED NATIONS, 2012).

O segundo componente do EGDI, denominado de índice de infraestrutura de telecomunicações, é o resultado de uma média aritmética composta de cinco indicadores relativos à capacidade infraestrutural de conectividade de telecomunicações de um determinado país no que tange à disponibilização de serviços públicos eletrônicos. A relação desses indicadores é a seguinte: estimativa de usuários de internet, quantitativo de linhas de telefone fixo, quantitativo de assinantes de telefone móvel, quantitativo de assinaturas de internet fixa e uso de internet de banda larga. A fonte primária desses dados é a International Telecommunication Union (ITU) (UNITED NATIONS, 2008, 2012).

\footnotetext{
${ }^{3}$ Disponível no sítio: http://www.w3.org/TR/WCAG/.
} 
O terceiro e último componente do EGDI, índice de capital humano, é composto de uma média ponderada de dois indicadores: taxa de alfabetização de adultos (com peso de dois terços) e taxa bruta combinada do grau de matrícula nos níveis de ensino fundamental, secundário e universitário (com peso de um terço). As fontes primárias desses dados são a United Nations Educational, Scientific and Cultural Organization (Unesco); o United Nations Development Programme (UNDP); e o Banco Mundial (UNITED NATIONS, 2012).

Por fim, o indicador suplementar denominado de participação eletrônica busca aferir a qualidade do quarto estágio (serviços conectados) do primeiro componente do EGDI (serviços online). Ele é obtido por meio de um questionário cujas perguntas se subdividem em três categorias focadas, respectivamente, no uso da internet como facilitador: da provisão de informações dos governos aos cidadãos para fins de tomada de decisão (e-information sharing); da interação com stakeholders com o objetivo de incrementar os processos deliberativos e a participação da sociedade (e-consultation); e do engajamento dos cidadãos, favorecendo seus inputs nos processos de tomada de decisão (e-decision making) (UNITED NATIONS, 2012). O Quadro 5 traz o framework do índice participação eletrônica.

Deve-se ressaltar que, enquanto o indicador serviços online busca medir a disponibilidade de informações e de serviços eletrônicos, o índice participação eletrônica tem como objetivo aferir a qualidade e o grau de utilidade dessas informações e serviços, com a finalidade de engajar os cidadãos no processo de formulação de políticas públicas, por intermédio de ferramentas de governo eletrônico que promovam ações deliberativas e a tomada de decisão participativa (UNITED NATIONS, 2004).

\section{Quadro 5 - Framework do índice participação eletrônica}

\begin{tabular}{|l|l|}
\hline Categoria & Descrição \\
\hline E-information & $\begin{array}{l}\text { Websites governamentais disponibilizam informações sobre } \\
\text { políticos eleitos, estrutura de governo, políticas e programas } \\
\text { governamentais, orçamento, leis e regulamentos e outras } \\
\text { questões de interesse público. Ferramentas online de } \\
\text { disseminação proporcionam o acesso e o uso de informações, } \\
\text { incluindo fóruns na Web, redes comunitárias, blogs, listas de } \\
\text { e-mail, mensagens de texto (microdemocracia), grupos de } \\
\text { notícias e salas de chat. Este componente da pesquisa avalia } \\
\text { se os governos estão disponibilizando o tipo de informação } \\
\text { que encoraja a participação da sociedade, provendo-lhes } \\
\text { empowerment. Isso inclui a publicação online de políticas } \\
\text { de participação eletrônica, calendários de discussão online e } \\
\text { ferramentas de notificação eletrônica. }\end{array}$ \\
\hline
\end{tabular}




\begin{tabular}{|c|c|}
\hline Categoria & Descrição \\
\hline E-consultation & $\begin{array}{l}\text { Os governos encorajam os cidadãos a participar de discussões, } \\
\text { oferecendo e explicando os mecanismos e ferramentas de } \\
\text { consulta eletrônica, disponibilizando a escolha de tópicos } \\
\text { online sobre políticas públicas para discussão em tempo real } \\
\text { e acesso a arquivos de áudios e vídeos de reuniões públicas. } \\
\text { É franqueado aos cidadãos a pauta da agenda de debate por } \\
\text { meio de petições eletrônicas (e-petitioning). Os governos } \\
\text { certificam-se que os políticos tenham um website usado } \\
\text { para comunicar-se diretamente com seus representados, } \\
\text { provendo-lhes feedback sobre assuntos de seu interesse. } \\
\text { Este componente da pesquisa avalia os meios utilizados para } \\
\text { solicitar as opiniões dos cidadãos, feedback e input por meio } \\
\text { de pesquisas online, salas de chat, mensagens instantâneas, } \\
\text { blogs etc. }\end{array}$ \\
\hline E-decision making & $\begin{array}{l}\text { O governo indica que levará em consideração os inputs } \\
\text { eletrônicos dos cidadãos nos seus processos de tomada } \\
\text { de decisão, dando-lhes retorno dos resultados de decisões } \\
\text { tomadas com base em processos de consulta à sociedade. } \\
\text { Este componente da pesquisa avalia a extensão em que os } \\
\text { países estão comprometidos com o empowerment de seus } \\
\text { cidadãos, bem como consideram seus pontos de vista nos } \\
\text { processos de tomada de decisão na formulação de políticas } \\
\text { públicas. }\end{array}$ \\
\hline
\end{tabular}

Fonte: Elaboração própria a partir de informações provenientes de United Nations (2012).

A variável utilizada nesta pesquisa denominada de voz e responsabilização busca capturar as percepções da extensão em que os cidadãos de determinado país ou território são capazes de participar da escolha de seus governos, assim como as liberdades de expressão e de associação e a liberdade dos meios de comunicação, bem como a responsabilização dos agentes públicos. Esse indicador é construído a partir de 17 fontes provenientes de surveys e de experts dos setores público, privado e não governamental, cujas características se encontram descritas no Quadro 6, a seguir. 
Quadro 6 - Descrição das fontes do indicador voz e responsabilização

\begin{tabular}{|c|c|c|}
\hline Fonte & $\begin{array}{l}\text { Cobertura } \\
\text { de países/ } \\
\text { territórios }\end{array}$ & Aspectos analisados \\
\hline Afrobarometer & 19 & $\begin{array}{l}\text { Liberdade e justiça das eleições, } \\
\text { satisfação com a democracia, } \\
\text { confiança no parlamento }\end{array}$ \\
\hline Bertelsmann Transformation Index & 125 & $\begin{array}{l}\text { Participação política, estabilidade } \\
\text { institucional, integração social e } \\
\text { política }\end{array}$ \\
\hline $\begin{array}{l}\text { Cingranelli Richards Human Rights } \\
\text { Database and Political Terror Scale }\end{array}$ & 192 & $\begin{array}{l}\text { Liberdade de participação na } \\
\text { política }\end{array}$ \\
\hline $\begin{array}{l}\text { Economist Intelligence Unit Riskwire } \\
\text { \& Democracy Index }\end{array}$ & 181 & $\begin{array}{l}\text { Responsabilização dos agentes } \\
\text { públicos, índice de democracia }\end{array}$ \\
\hline Freedom House & 197 & $\begin{array}{l}\text { Liberdade de expressão e de } \\
\text { associação }\end{array}$ \\
\hline $\begin{array}{l}\text { Freedom House Countries at the } \\
\text { Crossroads }\end{array}$ & 62 & Responsabilização e direito à voz \\
\hline Gallup World Poll & 130 & Confiança em eleições honestas \\
\hline $\begin{array}{l}\text { Global Insight Business Conditions } \\
\text { and Risk Indicators }\end{array}$ & 203 & $\begin{array}{l}\text { Como a população pode ser } \\
\text { ouvida por seus representantes }\end{array}$ \\
\hline Global Integrity Index & 79 & $\begin{array}{l}\text { Organização da mídia, acesso } \\
\text { público à informação, participação } \\
\text { dos cidadãos nas eleições }\end{array}$ \\
\hline $\begin{array}{l}\text { IFAD Rural Sector Performance } \\
\text { Assessments }\end{array}$ & 90 & $\begin{array}{l}\text { Diálogo entre governo e } \\
\text { organizações rurais }\end{array}$ \\
\hline Institutional Profiles Database & 85 & $\begin{array}{l}\text { Direitos políticos, funcionamento } \\
\text { das instituições políticas, liberdade } \\
\text { de imprensa e de associação, } \\
\text { respeito pelas minorias, liberdade } \\
\text { de movimentação }\end{array}$ \\
\hline $\begin{array}{l}\text { International Research and } \\
\text { Exchanges Board Media } \\
\text { Sustainability Index }\end{array}$ & 76 & $\begin{array}{l}\text { Nível de sustentabilidade da } \\
\text { imprensa }\end{array}$ \\
\hline Latinobarometro & 18 & $\begin{array}{l}\text { Satisfação com a democracia, } \\
\text { confiança no parlamento }\end{array}$ \\
\hline $\begin{array}{l}\text { Political Risk Services International } \\
\text { Country Risk Guide }\end{array}$ & 140 & $\begin{array}{l}\text { Presença de militares na política e } \\
\text { responsabilização democrática }\end{array}$ \\
\hline $\begin{array}{l}\text { Reporters Without Borders Press } \\
\text { Freedom Index }\end{array}$ & 170 & Liberdade de imprensa \\
\hline $\begin{array}{l}\text { Vanderbilt University Americas } \\
\text { Barometer }\end{array}$ & 23 & $\begin{array}{l}\text { Satisfação com a democracia, } \\
\text { confiança no parlamento }\end{array}$ \\
\hline $\begin{array}{l}\text { World Economic Forum Global } \\
\text { Competitiveness Report }\end{array}$ & 134 & Ausência de censura à mídia \\
\hline
\end{tabular}

Fonte: Elaboração própria a partir de informações provenientes de Kaufmann, Kraay e Mastruzzi (2010). 
A variável utilizada nesta pesquisa chamada de efetividade governamental busca capturar as percepções sobre a qualidade dos serviços públicos e dos servidores públicos e seu grau de independência quanto a pressões políticas; acerca da qualidade da formulação e implementação de políticas públicas; bem como sobre a credibilidade dos governos quanto ao compromisso com essas políticas. Esse indicador é construído a partir de 14 fontes provenientes de surveys e de experts dos setores público, privado e não governamental, cujas características se encontram descritas no Quadro 7.

\section{Quadro 7 - Descrição das fontes do indicador efetividade governamental}

\begin{tabular}{|c|c|c|}
\hline Fonte & $\begin{array}{l}\text { Cobertura } \\
\text { de países/ } \\
\text { territórios }\end{array}$ & Aspectos analisados \\
\hline $\begin{array}{l}\text { African Development Bank } \\
\text { Country Policy and Institutional } \\
\text { Assessments }\end{array}$ & 53 & $\begin{array}{l}\text { Gestão dos recursos públicos, } \\
\text { políticas de aperfeiçoamento da } \\
\text { eficiência do setor público, qualidade } \\
\text { da administração pública }\end{array}$ \\
\hline Afrobarometer & 19 & $\begin{array}{l}\text { Gestão da água e dos serviços de } \\
\text { saneamento, gestão das estradas e } \\
\text { das pontes, gestão do fornecimento } \\
\text { de eletricidade, gestão dos serviços } \\
\text { de saúde, gestão dos serviços de } \\
\text { educação }\end{array}$ \\
\hline $\begin{array}{l}\text { Asian Development Bank } \\
\text { Country Policy and Institutional } \\
\text { Assessments }\end{array}$ & 29 & Gestão do orçamento público \\
\hline $\begin{array}{l}\text { Bertelsmann Transformation } \\
\text { Index }\end{array}$ & 125 & $\begin{array}{l}\text { Capacidade de governança pública, } \\
\text { uso efetivo dos recursos }\end{array}$ \\
\hline $\begin{array}{l}\text { Business Enterprise Environment } \\
\text { Survey }\end{array}$ & 27 & $\begin{array}{l}\text { Qualidade das telecomunicações, da } \\
\text { eletricidade e dos transportes e seu } \\
\text { impacto nos negócios }\end{array}$ \\
\hline $\begin{array}{l}\text { Economist Intelligence Unit } \\
\text { Riskwire \& Democracy Index }\end{array}$ & 181 & $\begin{array}{l}\text { Qualidade da burocracia, excesso de } \\
\text { burocracia }\end{array}$ \\
\hline Gallup World Poll & 130 & $\begin{array}{l}\text { Satisfação com os transportes } \\
\text { públicos, com as rodovias e com o } \\
\text { sistema educacional }\end{array}$ \\
\hline Global Insight Global Risk Service & 144 & $\begin{array}{l}\text { Instabilidade governamental, falta de } \\
\text { efetividade governamental, e fracasso } \\
\text { institucional }\end{array}$ \\
\hline $\begin{array}{l}\text { Global Insight Business Conditions } \\
\text { and Risk Indicators }\end{array}$ & 203 & $\begin{array}{l}\text { Consistência das políticas públicas } \\
\text { e da continuidade do planejamento } \\
\text { governamental, e qualidade da } \\
\text { burocracia estatal }\end{array}$ \\
\hline
\end{tabular}




\begin{tabular}{|l|c|l|}
\hline \multicolumn{1}{|c|}{ Fonte } & $\begin{array}{l}\text { Cobertura } \\
\text { de países/ } \\
\text { territórios }\end{array}$ & \multicolumn{1}{|c|}{ Aspectos analisados } \\
\hline $\begin{array}{l}\text { IFAD Rural Sector Performance } \\
\text { Assessments }\end{array}$ & 90 & $\begin{array}{l}\text { Alocação e gestão de recursos } \\
\text { públicos para o desenvolvimento } \\
\text { rural }\end{array}$ \\
\hline $\begin{array}{l}\text { Institute for Management } \\
\text { and Development World } \\
\text { Competitiveness Yearbook }\end{array}$ & 55 & $\begin{array}{l}\text { Independência do serviço público } \\
\text { quanto à interferência política, } \\
\text { efetividade da implementação de } \\
\text { decisões de governo, índice de } \\
\text { burocracia, distribuição de bens e } \\
\text { serviços públicos }\end{array}$ \\
\hline $\begin{array}{l}\text { Institutional Profiles Database } \\
\text { Lelações entre governo e cidadãos, } \\
\text { qualidade do fornecimento de bens } \\
\text { públicos: educação e saúde }\end{array}$ \\
\hline Latinobarometro & 85 & Confiança no governo \\
\hline $\begin{array}{l}\text { Political Risk Services } \\
\text { International Country Risk Guide }\end{array}$ & 140 & Qualidade da burocracia \\
\hline
\end{tabular}

Fonte: Elaboração própria a partir de informações provenientes de Kaufmann, Kraay e Mastruzzi (2010).

\section{Apresentação e discussão dos resultados}

\section{H1: Um alto grau de participação eletrônica está positivamente correlacionado} com um alto grau de desenvolvimento do governo eletrônico, como um todo.

A fim de se analisar a associação entre o nível de participação eletrônica e o índice de desenvolvimento do governo eletrônico, como um todo, foram escolhidas as variáveis participação eletrônica e EGDI. Ao se empregar a técnica estatística denominada de correlação linear de Pearson, obteve-se o resultado de $r=0,726$ ( $N=192, p<0,001)$, o que caracteriza uma correlação de forte magnitude. $O$ respectivo coeficiente de determinação, obtido desse valor, é $r^{2}=0,5270$. Isso significa que as variáveis supracitadas guardam um percentual de 52,70\% de variância compartilhada. A partir desses resultados, utilizaram-se balizadores adicionais como forma de complementar os achados. Nesse caso, lançou-se mão das médias do índice de participação eletrônica e do EGDI.

Considerando-se os 65 países posicionados acima da média do indicador participação eletrônica $(0,2236)$, constata-se que 59 também apresentam índices acima da média do $\operatorname{EGDI}(0,4896)$. Por outro lado, entre os 127 países dispostos abaixo da média do indicador participação eletrônica, verifica-se que 87 igualmente exibem índices abaixo da média do EGDI. A análise do Gráfico 1 ajuda a visualizar esses achados. Há um grupo de casos, mais disperso e mais deslocado da linha de tendência de correlação (quadrante superior), composto por países acima da média do indicador participação eletrônica e também acima da média do EGDI. 
A esse rol pertencem os líderes dos rankings de participação eletrônica e do EGDI, Coreia do Sul e Holanda. Situados abaixo desse grupo, no quadrante inferior direito do plano cartesiano, realçados no quadrante inferior direito, existem casos mais concentrados e mais próximos à linha de tendência; trata-se de países também acima da média do EGDI, mas abaixo da média do índice participação eletrônica, como, por exemplo, a Bélgica, 24ạ colocada em termos do EGDI, mas ocupante da longínqua 89a posição em função da participação eletrônica.

\section{Gráfico 1 - Relação entre participação eletrônica e EGDI}

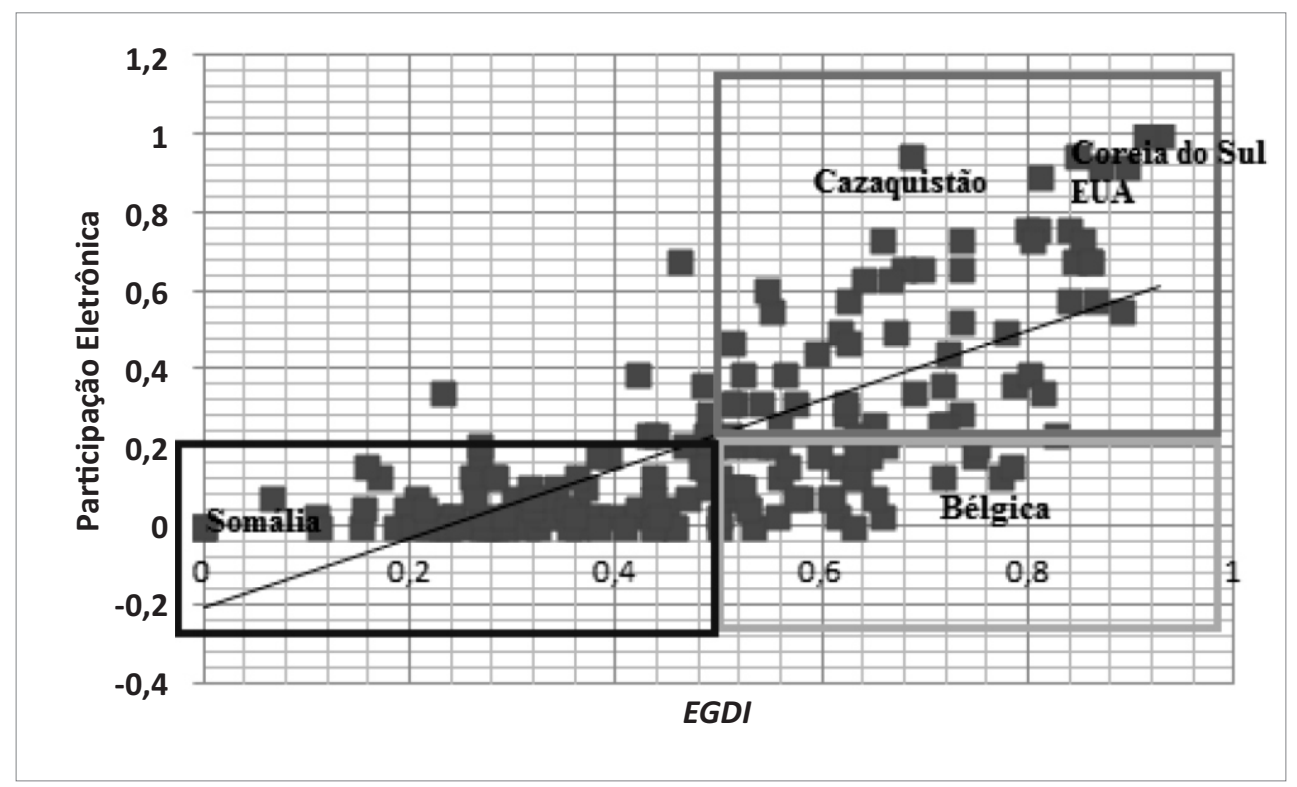

Fonte: Elaboração própria.

Um terceiro grupo, ainda mais concentrado e mais próximo à linha de tendência, é formado por países igualmente abaixo da média do EGDI e da média do indicador participação eletrônica, como é o caso da Somália, 4ạ pior colocada pelo ranking do EGDI e ocupante da 123a posição no ranking de participação eletrônica. Por fim, constata-se a existência de alguns poucos casos não enquadrados em nenhuma das três categorias descritas anteriormente; trata-se de países afastados da linha de tendência de correlação apresentada, detentores de índices de participação eletrônica acima da média e valores do EGDI abaixo da média internacional para esse indicador.

Em virtude desses achados e constatações adicionais, conclui-se que a primeira hipótese desta pesquisa foi aceita, ou seja, quanto maior o grau de participação eletrônica, maior tende a ser o grau de desenvolvimento do governo eletrônico, como um todo. 
H2: Um alto grau de participação eletrônica está positivamente correlacionado com um alto grau de desenvolvimento do governo eletrônico, especificamente no que tange à disponibilização de informações e serviços.

Com o objetivo de se examinar o relacionamento entre o grau de participação eletrônica e o nível de desenvolvimento do governo eletrônico, nomeadamente o que se refere à disponibilização de informações e serviços, selecionaram-se as variáveis participação eletrônica e serviços online. Chegou-se, então, ao resultado do teste de análise bivariada (correlação linear de Pearson): $r=0,889$ ( $N=192$, $p<0,001)$, valor que denota a existência de uma forte associação entre as variáveis em questão. Ao derivar-se o coeficiente de determinação dessa relação, obtémse $r^{2}=0,7903$, cujo significado é que $79,03 \%$ da variância nos escores do indicador participação eletrônica podem ser explicadas pela variância nos escores do índice serviços online; por outro lado, isso também significa que somente $20,97 \%$ da variância entre as variáveis supracitadas são explicados por outros fatores.

Com o intuito de se confirmar esses resultados, foram empregados critérios complementares de análise: a média do indicador participação eletrônica e a média do índice serviços online. Na faixa superior, entre os 65 países situados acima da média do indicador participação eletrônica $(0,2236)$, constata-se que apenas três não estão acima da média do índice serviços online $(0,4343)$. Na faixa inferior, entre os 127 países abaixo da média do indicador participação eletrônica, nota-se que 87 ostentam valores abaixo da média do índice de serviços online. O Gráfico 2 permite a observação dessas constatações.

\section{Gráfico 2 - Relação entre participação eletrônica e serviços online}

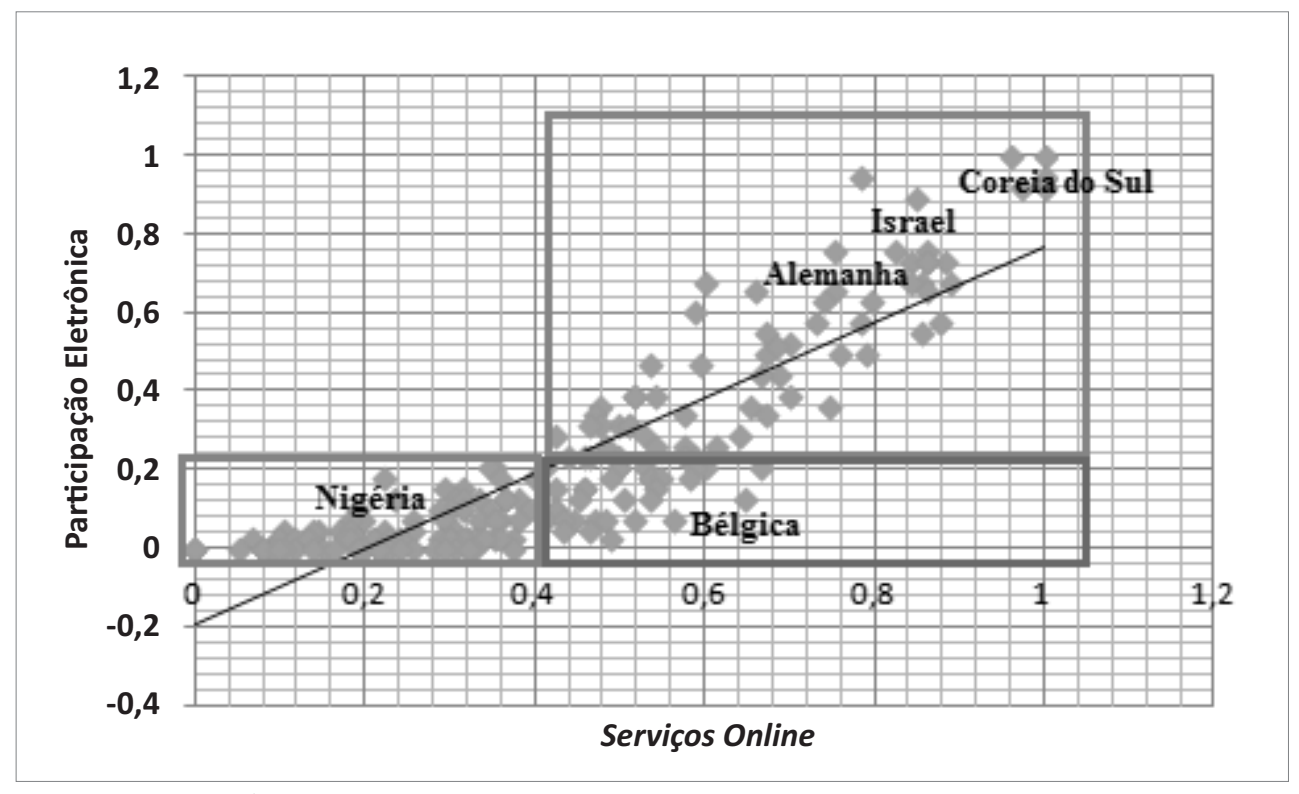

Fonte: Elaboração própria. 
Verifica-se, mais uma vez, a forte concentração de casos (127) abaixo da média do indicador participação eletrônica. Além disso, é claro o agrupamento em torno da linha de tendência apresentada, confirmando o forte grau de correlação encontrado no teste paramétrico. A distribuição dos casos pode ser nitidamente dividida em três agrupamentos. O primeiro, localizado no quadrante superior direito do plano cartesiano, reúne países acima da média do indicador participação eletrônica e também acima da média do índice serviços online. A esse grupo pertence a Coreia do Sul, líder dos rankings de participação eletrônica e de serviços online.

Logo abaixo desse grupo há outra reunião de casos, realçados no quadrante inforior direito, composta por países igualmente acima da média do indicador serviços online, mas abaixo da média do índice participação eletrônica, como é o caso da Bélgica. O terceiro agrupamento, mais concentrado e mais próximo à linha de tendência que os demais, representa países abaixo da média tanto do indicador participação eletrônica quanto do índice de serviços online, como a Nigéria. Por fim, constata-se que nenhum caso deixa de se enquadrar nas três categorias descritas anteriormente, ou seja, não há países que ostentam índices de participação eletrônica acima da média conjugados com índices de serviços online abaixo da média mundial.

Por todas essas constatações e resultados, a conclusão a que se chega é que a segunda hipótese desta pesquisa foi aceita: elevados graus de participação eletrônica estão fortemente associados com altos níveis de desenvolvimento do governo eletrônico, especificamente no que tange à disponibilização de informações e serviços.

A aceitação da primeira e da segunda hipótese deste trabalho, em conjunto, conforme exposto anteriormente, confirma empiricamente o que a literatura tem associado na teoria: o desenvolvimento do governo eletrônico e a participação eletrônica (Alonso; Ferneda; Braga, 2011; Bimber, 2000, 2001; Center for Democracy ANd TeCHNOlogy, 2002; ChAdWICK; MAY, 2003; Coleman, 1999; DAWES; GregG; AgourIS, 2004; EUROPEAN COMMUNITIES, 2003; GIBSON; LUSOLI; WARD, 2005; JAEGER, 2003; KERSTEN, 2003; LAMBRINOUDAKIS et al., 2003; LÉVY, 2004; LÖFSTEDT, 2005; MisuraCA, 2009; NATIONAL INFORMATION SOCIETY AgENCY, 2008; PINA; TORRES; Royo, 2007; REeCE, 2006; ROBERTSON; VATRAPU, 2010; StAHL, 2005; StARR, 2010; United Nations, 2003, 2004, 2005a, 2005b, 2008; United Nations; AMERICAN SOCIETY FOR PUBLIC AdMinistration, 2002).

Além disso, os resultados dos dois testes paramétricos, confrontando o desenvolvimento do governo eletrônico com a participação eletrônica, trouxeram à tona uma contribuição não prevista anteriormente na teoria: a variância nos 
escores referentes à participação eletrônica pode ser mais explicada pela variância nos escores relativos à disponibilização de informações e serviços eletrônicos aos cidadãos $(79,03 \%)$ do que pelo desenvolvimento do governo eletrônico como um todo $(52,70 \%)$.

H3: Quanto mais elevado o nível de participação eletrônica, mais elevado o nível de efetividade governamental.

Objetivando-se verificar o relacionamento entre o grau de participação eletrônica e o índice de efetividade governamental, foram escolhidas as variáveis participação eletrônica e efetividade governamental. Obteve-se, então, o coeficiente de correlação linear de Pearson $r=0,619$ ( $N=190, p<0,001)$, ou seja, uma forte correlação. Derivando-se esse valor, obtém-se o coeficiente de determinação $r^{2}=0,3831$. O significado desse resultado é que as variáveis associadas apresentam $38,31 \%$ de variância compartilhada.

Tais achados devem, então, ser ratificados por intermédio de parâmetros complementares, como a média do índice de participação eletrônica e as categorias de governança ${ }^{4}$. Considerando-se os 63 países do terço superior da distribuição, considerados "sem problemas de governança" (índice de efetividade governamental entre 0,1943 e 2,2478), verifica-se que 24 situam-se abaixo da média de participação eletrônica $(0,2236)$. Entre os 64 países do terço intermediário de distribuição, denominados de "neutros" (índice de Efetividade Governamental entre -0,6288 e $0,1831)$, constata-se que 44 estão abaixo da média internacional de participação eletrônica. Já entre os 63 países do terço inferior de distribuição, classificados "com problemas de governança" (índice de efetividade governamental entre -2,2416 e -0,6311), somente 5 se posicionam acima da média de participação eletrônica. Analisando-se o Gráfico 3, constatam-se visualmente os achados descritos.

Em primeiro lugar, percebe-se que há grupos de casos mais dispersos e outros mais concentrados. O quadrante superior direito é um agrupamento mais disperso, composto por países com índices acima da média de participação eletrônica e "sem problemas de governança". A esse grupo pertencem os líderes do ranking de efetividade governamental, Cingapura $(2,2478)$, Finlândia $(2,2407)$ e Dinamarca $(2,1669)$, e os líderes do ranking de participação eletrônica, Coreia do Sul e

\footnotetext{
${ }^{4}$ As categorias de governança decorrem da possibilidade teórica de se reunir os países em três amplos grupos, com intervalo de confiança de 90\%: primeiro, aqueles que são considerados "com problemas de governança", que correspondem ao grupo de casos situados no terço inferior da distribuição das variáveis; segundo, aqueles países que são denominados de "neutros", posicionados no terço intermediário da distribuição das variáveis; terceiro e último, aqueles países que são classificados como "sem problemas de governança", que se referem ao grupo de casos que se encontra no terço superior da distribuição das variáveis (UNITED NATIONS, 2007).
} 
Holanda. No quadrante inforior direito, também há uma reunião de casos mais dispersa, composta por países abaixo da média mundial de participação eletrônica, mas "sem problemas de governança", como a Irlanda. O terceiro agregado de casos dispersos (quadrante inferior esquerdo) é integrado por países acima da média de participação eletrônica e pertencentes à categoria de governança dos "neutros", como o Cazaquistão.

\section{Gráfico 3 - Relação entre participação eletrônica e efetividade governamental}

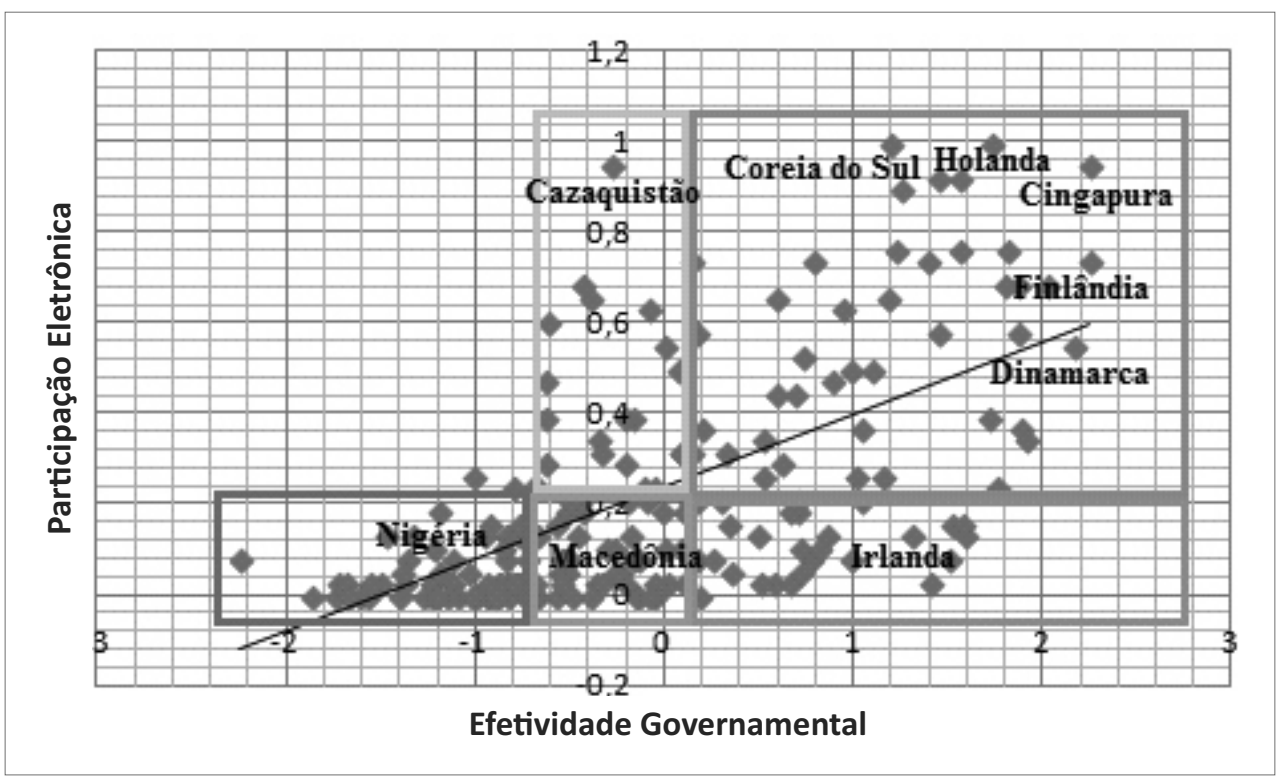

Fonte: Elaboração própria.

Quanto aos grupos mais concentrados, há duas divisões, ambas situadas abaixo da média de participação eletrônica. Da primeira, destacada no quadrante inforior central, fazem parte países da classe de governança dos "neutros", como, por exemplo, a Macedônia. Da segunda divisão de casos, destacada no quadrante inforior esquerdo, fazem parte países classificados na categoria de "com problemas de governança", como a Nigéria. Praticamente não há casos situados acima da média de participação eletrônica "com problemas de governança".

Conclui-se, destarte, pela aceitação da terceira hipótese desta pesquisa: altos graus de participação eletrônica tendem a estar fortemente associados com altos índices de efetividade governamental.

A aceitação da terceira hipótese deste trabalho, conforme exposto anteriormente, confirma empiricamente o que a literatura tem associado na teoria: a participação eletrônica e a efetividade governamental (BRAGA et al., 2008; DAWES, 2008; 
EUROPEAN UNION, 2001; HAMMERMAN, 2005; LIM; TANG, 2008; LÖFSTEDT, 2005; Misuraca, 2009; PINA; TORRES; Royo, 2007; Polat, 2005; Robertson; VATRAPU, 2010).

H4: Quanto mais elevado o nível de participação eletrônica, mais elevado o nível de responsabilização dos agentes públicos (accountability).

A fim de se analisar a associação entre o grau de participação eletrônica e o índice de responsabilização dos agentes públicos, foram escolhidas as variáveis participação eletrônica e voz e responsabilização. Ao empregar-se a técnica estatística (correlação linear de Pearson), obteve-se o resultado de $r=0,313$ $(N=192, p<0,001)$, o que caracteriza uma correlação de média magnitude. O respectivo coeficiente de determinação, obtido desse valor, é $r^{2}=0,0979$. Isso significa que $9,79 \%$ da variância nos escores do indicador participação eletrônica podem ser explicadas pela variância nos escores do indicador voz e responsabilização (e vice-versa). Foram usados, então, critérios auxiliares a fim de se confirmar esses resultados: média do índice participação eletrônica e categorias de governança.

No estrato superior dos 64 países qualificados como "sem problemas de governança" (índice de voz e responsabilização entre 0,4937 e 1,6182), constatase que metade (32 casos) se posiciona acima da média de participação eletrônica $(0,2236)$. Entre os 64 países do estrato mediano, da classe dos "neutros" (índice de voz e responsabilização entre -0,5327 e 0,4856), nota-se que pouco mais de um quarto (16) está situado acima da média de participação eletrônica. No estrato inferior, entre os 64 países do conjunto "com problemas de governança" (índice de voz e responsabilização entre -2,2078 e -0,5578), somente 16 se posicionam acima da média de participação eletrônica. O Gráfico 4, apresentado a seguir, ilustra essas constatações.

Em primeiro lugar, fica bastante evidente que a maior parte dos países (127) se posiciona abaixo da média de participação eletrônica. Além disso, os casos podem ser divididos em seis setores. Os três primeiros, compostos de casos acima da média de participação eletrônica, são grupos mais dispersos. No quadrante superior direito, enquadram-se os países "sem problemas de governança", como os líderes do ranking de voz e responsabilização, Noruega e Suíça, e os líderes do ranking de participação eletrônica, Coreia do Sul e Holanda. Realçados no quadrante superior central se encontram os países integrantes da categoria de governança de "neutros", como, por exemplo, Cingapura. No retângulo da cor violeta, por sua vez, posicionam-se os países "com problemas de governança", como a Arábia Saudita. 
Gráfico 4 - Relação entre participação eletrônica e voz e responsabilização

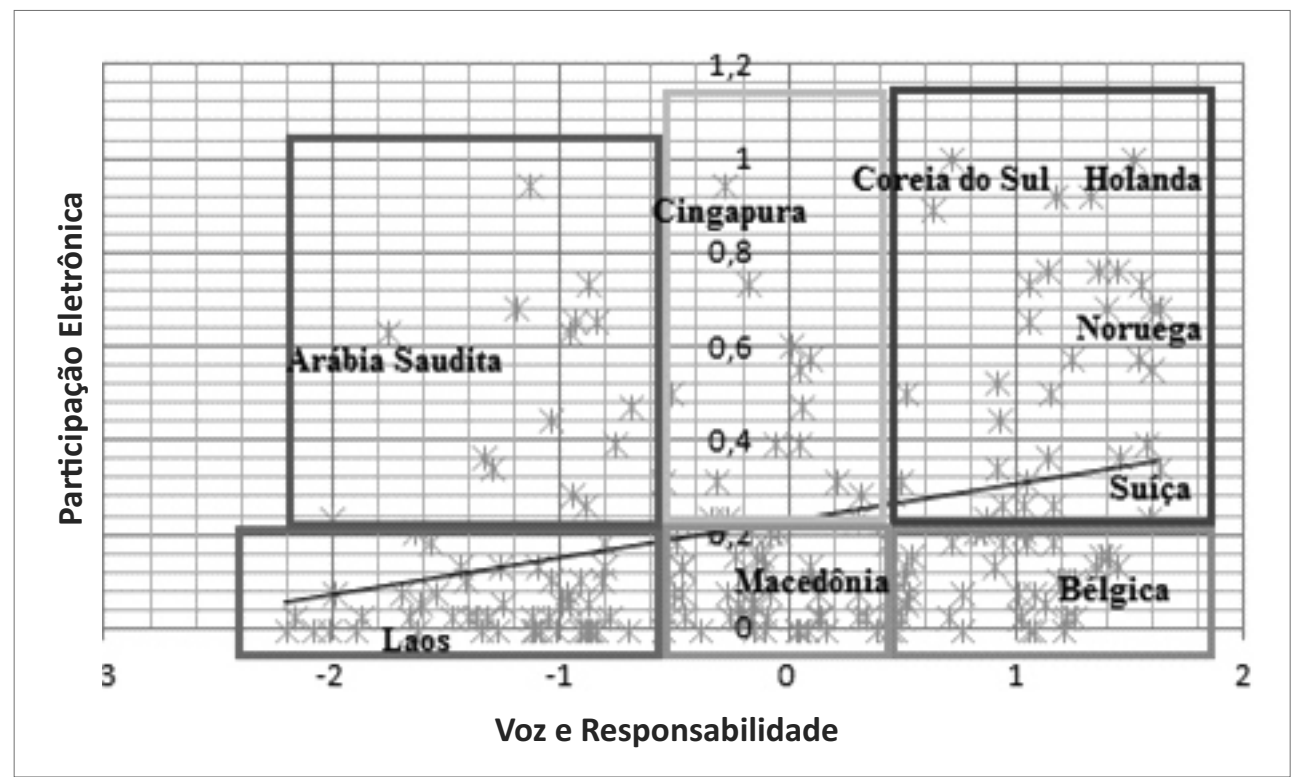

Fonte: Elaboração própria.

Os três outros setores, compostos de países abaixo da média de participação eletrônica, são grupos mais concentrados, pois reúnem mais de dois terços da distribuição dos casos analisados. No quadrante inferior direito, agrupam-se países "sem problemas de governança", como a Bélgica. No quadrante inferior central, situam-se os países da categoria de governança denominada de "neutros"; aqui se encontra, por exemplo, a Macedônia. O quadrante inferior esquerdo, por fim, agrega países "com problemas de governança", como é o caso de Laos.

A par dessas constatações, a conclusão é que a quarta hipótese desta pesquisa foi aceita, porque foi comprovada a associação positiva de média magnitude entre elevados graus de participação eletrônica e altos índices de responsabilização dos agentes públicos (accountability).

A aceitação da quarta hipótese deste trabalho, conforme exposto anteriormente, confirma empiricamente o que a literatura tem associado na teoria: a participação eletrônica e a responsabilização dos agentes públicos (BRAGA et al., 2008; DAWES, 2008; EUROPEAN UNION, 2001; HAMMERMAN, 2005; LIM; TANG, 2008; LÖFSTEDT, 2005; Misuraca, 2009; PINA; TORRES; Royo, 2007; Polat, 2005; Robertson; Vatrapu, 2010).

O Quadro 8, apresentado a seguir, traz um sumário dos resultados dos testes de hipóteses realizados nesta seção, agrupados por categorias de análise desenvolvidas a partir do modelo teórico de pesquisa. 


\section{Quadro 8 - Sumário dos resultados dos testes de hipóteses por categorias de análise}

\begin{tabular}{|c|c|c|}
\hline $\begin{array}{l}\text { Categorias de } \\
\text { análise }\end{array}$ & Hipótese & Resultado \\
\hline \multirow[b]{2}{*}{ Participação eletrônica } & $\begin{array}{l}\text { H1: Um alto grau de participação eletrônica } \\
\text { está positivamente correlacionado com um alto } \\
\text { grau de desenvolvimento do governo eletrônico, } \\
\text { como um todo. }\end{array}$ & Aceita \\
\hline & $\begin{array}{l}\text { H2: Um alto grau de participação eletrônica } \\
\text { está positivamente correlacionado com um alto } \\
\text { grau de desenvolvimento do governo eletrônico, } \\
\text { especificamente no que tange à disponibilização } \\
\text { de informações e serviços. }\end{array}$ & Aceita \\
\hline $\begin{array}{l}\text { Participação eletrônica e } \\
\text { efetividade } \\
\text { governamental }\end{array}$ & $\begin{array}{l}\text { H3: Quanto mais elevado o nível de participação } \\
\text { eletrônica, mais elevado o nível de efetividade } \\
\text { governamental. }\end{array}$ & Aceita \\
\hline $\begin{array}{l}\text { Participação eletrônica e } \\
\text { accountability }\end{array}$ & $\begin{array}{l}\text { H4: Quanto mais elevado o nível de } \\
\text { participação eletrônica, mais elevado o nível } \\
\text { de responsabilização dos agentes públicos } \\
\text { (accountability). }\end{array}$ & Aceita \\
\hline
\end{tabular}

Fonte: Elaboração própria.

\section{Conclusões}

A ideia de se estudar as relações entre o desenvolvimento do governo eletrônico e temas como participação eletrônica, efetividade governamental e accountability surgiu da necessidade de se aprofundar a compreensão sobre o estágio atual de transição pelo qual passa a administração pública, a partir de um modelo que já não responde efetiva e tempestivamente às demandas da sociedade, em direção ao paradigma denominado de Governança Responsiva.

A literatura do setor público tem, frequentemente, apontado a emergência de novas tecnologias de informação e comunicação (TIC), e seus desdobramentos, como fatores de impulso à referida mudança. Isso se deve a características como automação e digitalização dos processos, virtualização das interações, interatividade e ubiquidade, que favorecem a participação eletrônica em um ambiente marcado pela transparência e pela crescente cobrança por maiores graus de efetividade e responsabilização dos agentes públicos.

Muito embora a literatura seja farta em trabalhos que vinculam o desenvolvimento do governo eletrônico a várias propriedades da governança do setor público, a realização de estudos empíricos, objetivando comprovar essas 
correlações, é bastante escassa. Tal constatação decorre, em primeiro lugar, da natureza complexa dos dois referidos campos do conhecimento; em segundo lugar, do estágio de desenvolvimento incipiente em que se encontram os trabalhos sobre governo eletrônico e também sobre governança do setor público. A presente pesquisa buscou, portanto, preencher essa lacuna.

A análise dos dados coletados revelou que um alto grau de participação eletrônica está positivamente correlacionado a um alto grau de desenvolvimento do governo eletrônico, como um todo. Evidenciou-se, ainda, que um alto grau de participação eletrônica está positivamente correlacionado a um alto grau de desenvolvimento do governo eletrônico, particularmente no que tange à disponibilização de informações e serviços.

Especificamente, a participação eletrônica está mais correlacionada ao desenvolvimento do governo eletrônico no que se refere à disponibilização de informações e serviços pelos governos. Essa constatação traz um novo elemento teórico sobre os temas abordados nesta pesquisa, pois não havia sido prevista na revisão de literatura.

Foi verificado, ainda, que quanto mais elevado o nível de participação eletrônica, mais elevado o nível de efetividade governamental. E também foi constatado que, quanto mais elevado o nível de participação eletrônica, mais elevado o nível de accountability, muito embora se trate de uma associação de força média.

Em particular, a participação eletrônica está mais fortemente associada ao desenvolvimento do governo eletrônico do que à accountability ou à efetividade governamental.

Por fim, este trabalho, em função de limitações intrínsecas, como tempo restrito ou delimitação do objeto de estudo, e limitações extrínsecas, como a indisponibilidade de dados, suscita uma série de trabalhos futuros. Em primeiro lugar, as categorias de análise construídas a partir do modelo teórico da presente pesquisa poderiam ser utilizadas em estudos que se utilizassem de bases de dados distintas das que foram selecionadas para este trabalho.

Em segundo lugar, seria possível realizar, com as mesmas categorias desta pesquisa, estudos de corte longitudinal, com grupos menores de países, por regiões, por grupos econômicos, ou mesmo poderiam ser realizados estudos sobre casos individuais. Em terceiro lugar, poderiam ser levados a cabo outros trabalhos empíricos, a partir dessas mesmas categorias de análise, mas empregando-se uma estratégia de pesquisa diversa, qual seja, qualitativa, fruto de uma abordagem indutiva e subjetiva dos fenômenos.

Em quarto e último lugar, havendo dados disponíveis para tal, seria possível realizar estudos que abordassem governo, participação eletrônica e accountability em função de outras categorias de análise como, por exemplo, a eficiência governamental. 


\section{Referências bibliográficas}

Abramson, J. B.; ARTERTON, C.; ORREN, g. r. The electronic commonwealth: the impact of new media technologies on democratic politics. New York: Basic Books, 1988.

Alonso, L. B. N.; FernedA, E.; BragA, L. V. Governo eletrônico e políticas públicas: análise sobre o uso da certificação digital no Brasil. Informação \& Sociedade: Estudos, v. 21, n. 2, p. 13-24, 2011.

AsSMANN, S.; MASLOW, S. "Digital government" in Japan: a selective survey of Japanese Ministry web sites. Asian Politics \& Policy, v. 2, n. 2, p. 291-294, 2010.

BAKRI, S. H. Development of e-government: a STOPE view. International Journal of Network Management, v. 14, n. 5, p. 339-350, 2004.

BARZELAY, M. The new public management: improving research and policy dialogue. Berkeley: University of California Press, 2001.

BASU, S. E-government and developing countries: an overview. International Review of Law, Computers \& Technology, v. 18, n. 1, p. 109-132, 2004.

BECKER, T. Rating the impact of new technologies on democracy. Communication of the ACM, v. 44, Issue 1, p. 39-43, 2001.

BEVIR, M.; RHODES, R.A.W; WeLlER, P. Traditions of governance: interpreting the changing role of the public sector. Public Administration, v. 81, n. 1, p. 1-17, 2003.

BIMBER, B. The study of information technology and civic engagement. Political Communication, v. 17, n. 4, p. 239-333, 2000.

Information and civic engagement in America: the search for political effect of the Internet. Political Research Quarterly, v. 54, n. 1, p. 53-67, 2001.

BRAGA, L. V. Inclusão digital: fator essencial ao progresso do governo eletrônico no Brasil. Revista de Políticas Públicas e Gestão Governamental: Res Pvblica, v. 6, n. 2, p. 53-76, 2007.

Certificação digital: a chave para um governo eletrônico seguro. Revista de Políticas Públicas e Gestão Governamental: Res Pvblica, v. 8, n. 2, p. 4559, 2009.

BRAGA, L. V. et al. O papel do governo eletrônico no fortalecimento da governança do setor público. Revista do Serviço Público, v. 59, n. 1, p. 5-21, 2008.

BRYMAN, A.; CRAMER, D. Quantitative data analysis with IBM SPSS 17, 18 \& 19: a guide for social scientists. Abingdon: Routledge, 2011.

Bryson, J. M.; Crosby, B. C.; Stone, M. M. The design and implementation of cross-sector collaborations: propositions form the literature. Public Administration Review, v. 66, Special Issue, p. 44-55, 2006.

CENTER FOR DEMOCRACY AND TECHNOLOGY. The e-government handbookfor developing countries. Washington, DC: The World Bank Information for Development Program, 2002.

CHADWICK, A.; MAY, C. Interaction between states and citizens in the age of the Internet: "e-government" in the United States, Britain, and the European Union. 
Governance: An International Journal of Policy, Administration, and Institutions, v. 16, n. 2, p. 271-300, 2003.

Coleman, S. Can the new media invigorate democracy? Political Quarterly, v. 70, n. 2, p. 16-22, 1999.

New mediation and direct representation: reconceptualizing representation in the digital age. New Media and Society, v. 7, n. 2, p. 177-198, 2005.

COMPAINE, B. M. (Ed.). The digital divide: facing a crisis or creating a myth? Cambridge: MIT Press Sourcebooks, 2001.

COOK, I.; HOROBIN, G. Implementing e-government without promoting dependence: open source software in developing countries in Southeast Asia. Public Administration and Development, v. 26, n. 4, p. 279-289, 2006.

DAHL, R. A. Polyarchy: participation and opposition. New Haven: Yale University Press, 1971.

DAle, A; ARBeR, S; Proctor, M. Doing secondary analysis. New York: HarperCollins, 1988.

DAWES, S. S. The evolution and continuing challenges of e-governance. Public Administration Review, v. 68, Special Issue, p. 86-102, 2008.

DAWES, S. S.; GREGG, V.; AGouRIS, P. Digital government research: investigations at the crossroads of social and information science. Social Science Computer Review, v. 22, n. 1, p. 5-10, 2004.

DUNLEAVY, P. et al. New public management is dead-long live digital-era governance. Journal of Public Administration Research and Theory, v. 16, n. 3, p. 467-494, 2006. DYSON, E. Release 2.1: a design for living in the digital age. London: Penguin, 1998. EMERSON, K.; NABATCHI, T.; BALOGH, S. An integrative framework for collaborative governance. Journal of Public Administration Research and Theory, v. 22, n. 1, p. 1-29, 2012.

EUROPEAN COMMUNITIES. The role of e-government for Europe's future. Brussels: Commission of the European Communities, 2003.

EUROPEAN UNION. European governance: a white paper. Brussels: Commission of the European Communities, 2001.

FAtToRe, G.; Dubois, H. F. W.; LAPEnTA, A. Measuring new public management and governance in political debate. Public Administration Review, v. 72, n. 2, p. 218-227, 2012.

Ferneda, E.; Alonso, L. B. N.; Braga, L. V. Digital certification in the Brazilian e-government. Journal of Information Systems and Technology Management, v. 8, n. 2, p. 331-346, 2011.

FISHKIN, J. S. Democracy and deliberation: new directions for democratic reform. New Haven: Yale University Press, 1991.

FREDERICKSON, H.G. Toward a theory of the public for public administration. Administration \& Society, v. 22, n. 4, p. 395-417, 1991. 
FUNG, A.; WRIGHT, E. O. Deepening democracy: institutional innovations in empowered participatory governance. New York: Verso, 2001.

GIBSON, R. K. Elections online: assessing Internet voting in light of the Arizona Democratic primary. Political Science Quarterly, v. 116, n. 4, p. 561-583, 2001.

New media and the revitalization of politics. Representation, v. 45, n. 3, p. 289-299, 2009.

GIBSON, R. K.; LUSOLI, W.; WARD, S. J. Online participation in the UK: testing a "contextualised" model of Internet effects. British Journal of Politics and International Relations, v. 7, n. 4, p. 561-583, 2005.

Hague, B.; LoAder, B. Digital democracy: Discussion and decision making in the Internet age. Abingdon: Routledge, 1999.

HAMMERMAN, C. Lessons learned in Michigan: best practices for local e-government. Bulletin of the American Society for Information Science and Technology, v. 31, n. 3, p. 17-19, 2005.

HEINTZE, T.; BRETSCHNEIDER, S. Information technology and restructuring in public organizations: does adoption of information technology affect organizational structures, communications, and decision making? Journal of Public Administration Research and Theory, v. 10, n. 4, p. 801-830, 2000.

Hyson, S. The ombudsman and e-government in Canada. Canadian Public Administration, v. 53, n. 2, p. 183-200, 2010.

JAEGER, P. T. The endless wire: e-government as global phenomenon. Government Information Quarterly, v. 20, n. 4, p. 323-331, 2003.

Johnston, E. Governance infrastructures in 2020. Public Administration Review, v. 70, Special Issue, p. 122-128, 2010.

KANG, S.; GEARHART, S. E-government and civic engagement: how is citizens' use of city web sites related with civic involvement and political behaviors? Journal of Broadcasting \& Electronic Media, v. 54, n. 3, p. 443-462, 2010.

KAUFMANN, D.; KRAAY, A.; MASTRUZZI, M. Worldwide governance indicators 2011 update: aggregate governance indicators 1996-2010. Washington, DC: The World Bank Development Research Group, 2011.

Kellogg, W. A.; Mathur, A. Environmental justice and information technologies: overcoming the information access paradox in urban communities. Public Administration Review, v. 63, n. 5, p. 573-85, 2003.

KERSTEN, G. E. E-democracy and participatory decision processes: lessons from e-negotiation experiments. Journal of Multi-Criteria Decision Analysis, v. 12, n. 2-3, p. 127-143, 2003.

KETTL, D. F. 2002. The transformation of governance: public administration for twenty-first century America. Baltimore: Johns Hopkins University Press, 2002.

Managing boundaries in American administration: the collaborative imperative. Public Administration Review, v. 66, Special Issue, p. 10-19, 2006.

KRAUT, R. et al. Internet paradox: a social technology that reduces social involvement and psychological well-being? American Psychologist, v. 53, n. 9, p. 1017-1072, 1998. 
KRUEGER, B. S. Assessing the potential of Internet political participation in the United States: a resource approach. American Politics Research, v. 30, n. 5, p. 476498, 2002.

LAMBRINOUDAKIS, C. et al. Security requirements for e-government services: a methodological approach for developing a common PKI-based security policy. Computer Communications, v. 26, n. 16, p. 1873-1883, 2003.

LAZARSFELD, P. Evidence and inference in social research. Daedalus, v. 87, Fall 1958, p. 99-130, 1958.

LEE, J. Internet politics: is it another new media with politics, or business, as usual? Review of Communication, v. 9, n. 2, p. 164-167, 2009.

LÉvy, P. Ciberdemocracia. Lisboa: Instituto Piaget, 2004.

LIM, J. H.; TANG, S. Democratization and environmental policy-making in Korea. Governance: An International Journal of Policy, Institution, and Administration, v. 15, n. 4, p. 561-82, 2002.

Urban e-government initiatives and environmental decision performance in Korea. Journal of Public Administration Research and Theory, v. 18, n. 1, p. 109-138, 2008.

LÖFSTEDT, U. E-government - assessment of current research and some proposals for future directions. International Journal of Public Information Systems, v. 2005, n. 1, p. 39-52, 2005.

MARLIN-BENNETT, r.; THORNTON, E. N. Governance within social media websites: ruling new frontiers. Telecommunications Policy, v. 36, Issue 6, p. 493-501, 2012.

Miguel-MolinA, M. E-government in Spain: an analysis of the right to quality e-government. International Journal of Public Administration, v. 33, n. 1, p. 1-10, 2010.

MisuRACA, G. C. E-government 2015: exploring m-government scenarios, between ICT-driven experiments and citizen-centric implications. Technology Analysis \& Strategic Management, v. 21, n. 3, p. 407-424, 2009.

NABATCHI, T. Addressing the citizenship and democratic deficits: exploring the potential of deliberative democracy for public administration. American Review of Public Administration, v. 40, n. 4, p. 376-99, 2010.

National Information Society Agency. Concepts and features of government 2.0 and 3.0. Seoul: The National Information Society Agency, 2008.

Negroponte, N. Being Digital. London: Coronet, 1995.

NoRRIS, P. Digital divide: civic engagement, information poverty, and the Internet worldwide. Cambridge: Cambridge University Press, 2001.

The bridging and bonding role of online communities. The Harvard International Journal of Press/Politics, v. 7, n. 3, p. 3-13, 2002.

Organisation fOR ECONOMIC COOPERATION AND DEVElopment. Promise and problems of e-democracy: challenges of online citizen engagement. Paris: OECD Publishing, 2003. 
Osborne, S. P. The New Public Governance? Public Management Review, v. 8, Issue 3, p. 377-387, 2006.

PETLEY, J. Panic stations: surveillance in the UK. Index on Censorship, v. 42, n. 1, p. 70-74, 2013.

PINA, V.; TORRES, L.; RoYo, S. Are ICTs improving transparency and accountability in the EU regional and local governments? An empirical study. Public Administration, v. 85, n. 2, p. 449-472, 2007.

POLAT, R. K. The Internet and democratic local governance: the context of Britain. The International Information \& Library Review, v. 37, n. 2, p. 87-97, 2005.

RASH, W. Politics on the nets: wiring the political process. New York: W. H. Freeman, 1997.

REECE, B. E-government literature review. Journal of E-Government, v. 3, n. 1, p. 69110, 2006.

RHEINGOLD, H. The virtual community: finding connection in a computerised world. London: Minerva, 1995.

RobertSON, S. P.; VATRAPU, R. K. Digital government. Annual Review of Information Science and Technology, v. 44, Issue 1, p. 317-364, 2010.

SChUEFElE, D. A.; NISBET, M. Being a citizen online: new opportunities and dead ends. The Harvard International Journal of Press/Politics, v. 7, n. 3, p. 55-75, 2002.

ScotT, J. K. "E" the people: do U.S. municipal government websites support public involvement? Public Administration Review, v. 66, n. 3, p. 341-53, 2006.

SHAH, D.; KWAK, N; HOLBERT, R. L. "Connecting" and "disconnecting" with civic life: patterns of Internet use and the production of social capital. Political Communication, v. 18, n. 2, p. 141-162, 2001.

SIRIANNI, C. Investing in democracy engaging citizens in collaborative governance. Washington, DC: Brookings Institution, 2009.

SKOCPOL, T. Diminished democracy: from membership to management in American civic life. Norman: University of Oklahoma Press, 2002.

STAHL, B. C. The paradigm of e-commerce in e-government and e-democracy. In: HUANG, W.; SIAU, K.; WEI, K. K. Electronic government strategies and implementation. Hershey: Idea Group Publishing, 2005. p. 1-19.

STANLEY, W.; WEARE, C. The effects of Internet use on political participation: evidence from an agency online discussion forum. Administration \& Society, v. 36, n. 5, p. 503-27, 2004.

STARR, P. The liberal state in a digital world. Governance: An International Journal of Policy, Administration, and Institutions, v. 23, n. 1, p. 1-6, 2010.

TOFfler, A.; TOFfler, H. Creating a new civilization: the politics of the third wave. Atlanta: Turner Publications, 1995.

TOLBERT, C. J; MCNEAL, R. S. Unraveling the effects of the Internet on political participation? Political Research Quarterly, v. 56, n. 2, p. 175-186, 2003.

UNITED NATIONS. UN global e-government survey 2003. New York: Department of Economic and Social Affairs, 2003. 
UN global e-government readiness report 2004: towards access for opportunity. New York: Department of Economic and Social Affairs, 2004.

UN global e-government readiness report 2005: from e-government to e-inclusion. New York: Department of Economic and Social Affairs, 2005a.

Unlocking the human potential for public sector performance. World public sector report 2005. New York: Department of Economic and Social Affairs, 2005b.

Public governance indicators: a literature review. New York: Department of Economic and Social Affairs, 2007.

UN e-government survey 2008: from e-government to connected governance. New York: Department of Economic and Social Affairs, 2008.

UN e-government survey 2012: e-government for the people. New York: Department of Economic and Social Affairs, 2012.

United Nations; AMERICAN SOCIETy fOR Public Administration. Benchmarking e-government: a global perspective. New York: United Nations Division for Public Economics and Public Administration, 2002.

UNITED NATIONS POPULATION DIVISION. World population prospects: the 2012 revision. New York: Department of Economic and Social Affairs, 2013.

WARSChAUER, M. Tecnologia e inclusão social: a exclusão digital em debate. São Paulo: Senac, 2006.

Weber, L.; Loumake, A.; Bergman, J. Who participates and why? An analysis of citizens on the Internet and the mass public. Social Science Computer Review, v. 21, n. 1, p. 26-42, 2001.

WellmAN, B. et al. Does the internet increase, decrease, or supplement social capital? American Behavioral Scientist, v. 45, n. 3, p. 436-455, 2001.

WORLD BANK. Use of ICT enabled tools for conducting Public Consultations. Washington, DC: World Bank, 2013.

Lamartine Vieira Braga

Possui doutorado em Administração pela Universidade de Brasília (UnB) e University of Edinburgh Business School (Reino Unido). Atualmente é Professor Colaborador da Fundação Getúlio Vargas (FGV). Contato: lamartine.braga@ gmail.com

Ricardo Corrêa Gomes

Possui pós-doutorado pela Georgia State University (Estados Unidos). Atualmente é Professor da Universidade de Brasília (UnB). Contato: <rgomes@unb.br 